\title{
Kas amka, kosatko või hoopis keegi muu?
}

\author{
Ülo Siimets
}

J elo oli põdrakarjast tulnud ja jõi pärast liha söömist lõkke ääres teed. Õhtu oli vaikne. Siin-seal pugesid ümisejad koobastest välja, vilistasid ja kadusid jälle koopasse. Veem istus kivil ja vaatles binokliga ümbrust. Tal oli ammu kõht täis ja ta näris nõndanimetatud tšuktši tubakat. See oli tavaline mahorka, mis segati savi, tee, tuha ja võib-olla veel millegagi, millest ei räägitud.

Segu närimine oli vanemate tšuktši meeste harrastus. Nad keerasid sellisest segust kuulid, mida hoiti plekk-karbiga vööl rippuvas kotis. Nende kuulide närimisest olid vanemate meeste huuled tihti mustad. Mehed ise ütlesid, et kuulikeste närimine pidavat jõudu juurde andma.

K orraga hakkas Veem binokliga teraselt silmitsema.

"Kakomei," hõikas ta.

"Mis lahti?" küsis J elo. "Kas keinin (tšuktši keeles pruunkaru, grisli)?"

Tšuktš ei vastanud, vaid ulatas talle binokli.

J elo vaatas ja nägi binoklis suurt valget looma all orus luusimas. Põhilise osa ajast oli ta pika kaela otsas olev pea allapoole, nagu sööks ta heina või sammalt.

"Geol oogide hobune on hulkuma pääsenud," ütles J elo Veemile oma arvamuse.

Selle peale hakkas Veem naerma ja ütles: "Rumal, see on ju amka (tšuktši keeles jääkaru). Nendel loomadel tuleb vahel loll mõte minna läbi Tšuktšimaa siseosa Wrangeli saare suunas, kus on “amkade sünnitusmaja”. Ta sööb murakaid, sest liha ei ole saada. Muidu armastab ta üle kõige hülgemaksa, aga ega ta põhjapõtradest ka ära ütle."

"Noh, kui ta on amka, siis võtan püssi ja Iasen ta maha," ütles J elo püsti tõustes ja telgi nurga juurest vintpüssi haarates.

See oli vana Vene kolmeliiniline vintpüss, valmistatud 1896. aastal. Tšuktšid ei armastanud eriti seda püssi, sest see oli raskeja seetõttu kaasaskandmiseks tülikas. Nii oligi see relv jäetud J el ole. 
J elo toimekuse peale lausus Ejgeli, kes oli teiste meeste juttu esialgu ükskõikselt jäl ginud:

"Ma tulen kaasa. Ega amkaga saa nalja teha. Ta on väga verejanuline ja ega sa üksi temaga hakkama saa."

Ta võttis oma jahikarabiini ja mehed hakkasid minema. Ka kaasas olev suur must valge kaelaga laika Palek jooksis neile järele. Tšuktšid kutsusid seda tüüpi laikasid nendejulguse tõttu karutapjateks. Ka Palek ei kartnud peaaegu kedagi. Ejgeli võttis suuna eemal oleva sopka suunas.

"Ronimesellesopka otsa, sealt on hea lasta, muidu ta tuleb nagu kiirrong sullekallale."

J elole see mõte eriti ei meeldinud, sest tal oli karujahist teine arusaamine.

"Mis me siin jamame. Meil on kaks vintpüssi. Kaksteist padrunit. Sellise paugutamisega võib mitu karu tappa."

"See ei ol e keinin, see on amka. Nendega on hoopis teised lood," vastas Ejgeli ja rühkis edasi sopka suunas.

Kui nad Iõpuks sopka otsa jõudsid ja sealt alla vaatasid, nägid nad jääkaru kauguses val ge tikutoosina.

"Noh, nüüd oleme küll liiga kaugel," torises J elo.

Ejgeli ei vastanud midagi. Ta võttis õlalt püssi, sihtis ja tulistas. Pauk kaikus sopkade vahel. Kuul tungis karust paremale samblasse. Karu ei olnud vist varem kunagi püsside ega jahimeestega tegemist teinud, sest ta jäi ainult seisma ja vaatas selles suunas, kus kuul samblassetungis.

“Han, han!” ässitas Ejgeli laikat jääkaru kallale. Koer tormas näidatud suunas. Ka järgmine kuul läks mööda. Siis veel ja veel. J elogi oli võtnud õlalt püssi ja püüdis karu tabada. Oli lastud juba kuus-seitse lasku, kui lõpuks õnnestus Ejgelil saata kuul karu tagumisse paremasse jal ga. Selle peale jääkaru möiratas, keeras ennast ümber ja hakkas tormama mäest üles. Ta liikus tõepoolest väga kiiresti ja otse läbi põõsaste meeste suunas.

Koer, kes siiamaani oli kartmatult karu suunas tormanud, tõmbas saba jalge vahele ja hakkas kiiresti tema eest põgenema. Mehed tulistasid, kuid ei sihtinud suurest erutusest kuigi täpselt ja kuulid lendasid loomast mööda. Laika jõudis meeste juurde tagasi ja varjus nende selja taha. Karu aga lähenes suure kiirusega. Varsti oli kaugus loomani ainult sada, siis üheksakümmend, siis kaheksakümmend meetrit. Ejgeli püss oli padrunitest tühi. Ta võttis värisevatel kätel padrunikoti ja hakkas laskemoona tühja pidemesse 


\section{Ülo Siimets}

toppima. Siis kiilus üks padrun kinni. Ejgeli võttis vöölt noa ja püüdis noaotsaga padrunit kassetis õigesseasendisse seada. Oli kuulda ainult koera hirmunud kiunumist ja Ejgel i ohkimist.

Karu muudkui lähenes. Kääbusseedermänni oksad paiskusid kahes suunas õhku, kui loom põõsastest läbi tormas.

J elotulistas. Mööda. Püssi oli jäänud veel viimane padrun. Ejgeli ei saanud ikka veel oma relva korda. Karuni ol i kõigest 30-40 meetrit. J el o sihtis hästi hoolikalt ja tulistas. Kuul tabas looma esimesse vasakusse jal ga põlvest ülal pool. Paarkümmend sentimeetri kõrgemale tabanud lask oleks olnud surmav. Karu kukkus üle pea, kuid oli hetke pärast jällejalul. Ta oli vist aru saanud, et vastastega ei maksa nalja teha, sest nad on temast tugevamad, ja ta tormas longates tuldud teed tagasi.

Ka J el o võttis vööl asuvast padrunikotist padruneid ja hakkas püssi laadima. Ejgeli kohmitses oma püssi kallal, vaatas J el ole otsa ja küsis: "Kuule! Sel karul olid liiga suured kõrvad. Need olid ju veel ümmargused ka ja ta nagu kiirgas silmadest. Kas sa ei pannud tähele?"

J elo arvas, et kõrvad olid karul tema arvates küll tavalised, ja lisas, et aeg oleks karu jälitama minna, sest veri on maas ja ega haavatud loom kaugele jõua.

“Mina ei lähe küll kuhugi. Lähen tagasi laagrisse, tuleka kaasa. Ketlja ei tahtnud, et me selle amka tapame."

"Mina ei tule kuhugi. Mina lähen haavatud loomalejärele. Meil vigastatud looma maha ei jäeta."

"Loll. Amka ootab sind kusagil põõsa taga ja sinust ei jää mi dagi järele."

Et J el o keel dus kangekael selt laagrisse tulemast ja Ejgeli jääkaru jälitamast, läks kumbki oma teed. Koer Ionkis Ejgelile järele.

J el o lei dis looma verised jäljed ja kiirustas neid mööda jääkarule järele. Lõpuks ta nägi teda. Loom oli suure tormamisega jõudnud järgmise sopka otsa. Tulistamiseks oli vahemaa liiga suur. J el o tormas põõsaste vahel joostes karule järele. Mäest allaminek läks kiiresti, kuid järgmise sopka otsa jõudmine ol i mäe li ga järsu tõusu tõttu raske. Hakkas juba hämarduma. Kui ta Iõpuks sopka otsa jõudis ja silmadega looma otsis, oli juba üsna pime. J elo ei näinud kusagil karu ja otsustas tulla hommikul varaval ges teda uuesti otsima. Ta läks sopka otsast alla orgu. Teised karjused hoidsid lõkketuld suurena ja nii oli kodutee kaugele näha. Kui ta sinna jõudis, 




J ääkarujaht. Zagorski muuseumi kogud. V. Lotšerovi \& R. Benjaminovi foto 1980.

leidis ta mehed Iõkkeääres istumas. Ejgeli oli läinud teistest eemale, istus kivi otsas, pobises midagi ja laulis kurval häälel:

"Iiiii, aaaaa, o0000, uuuuu..."

"Mis tal viga hakkas?" küsis J elo.

"Ejgeli jutustas, et loomal, keda te tulistasite, olid väga suured kõrvad. Ka koer kartis teda. Kas sa panid tähele, milline suu tal oli?"

"Mis siis, kui kõrvad olidki suured? Suu oli ikka nagu olema peab, suur ja punane."

"Sel juhul ta ei ol nudki amka, vaid rekken $\eta$," vastas Veem. “Nüüd loeb Ejgeli palveid ja loitsib, et ta meile kallale ei tuleks. Muidugi võis ta olla ka kosatko."

Selgus, et üks ketlja liikidest on rekkenn. See on paha vaim, kes elab maa sees. Tal on jääkaru kere, väga suured, roosad, kujult hiirekõrvu meenutavad kõrvad. Lõuad pidid ol ema punased ja aegajalt ol evat jahimehed näinud ta suust tulevaid sädemeid.

Paljudel rekken $\eta$ idel ol evat ainult üks silm. Nad pidavat inimestele jahti ja nende meelissaagi ks ol evat šamaanid. Kui kellelgi õnnestub tappa rekken $\eta$, olla ta õnnega koos, sest kui kasutada tema kõrvu pol ogis (tšuktši jarangas asuv riidega kaetud magamisase suvel õhukesest riidest, talvel põdranahkadest tehtud telk), ollakse kaitstud kõikide hal bade vaimude eest.

Kosatko on aga hiiglaslik valge karu, kelle nahk on nii tugev, nagu ol eks ta kaetud mingi tugeva valgeluu, näiteks mammutiluuga. See loom on tunduvalt kiirem ja kärmem kui tavaline jääkaru. 


\section{Ülo Siimets}

Kõik karjused kardavad teda, sest ta armastab inimliha ja on lausa inimsööja. Vahel peibutab ta põõsaste vahel oma nutulesarnaneva häälega inimesi. Kes ta lähedusse sattub, see rebitakse lõhki ja süüakse ära. Oma kiiruse tõttu kutsutakse teda vahel rebane-jääkaruks.

Sel õhtul kaikusid Ejgeli joigumine ja pobin kaua sopkade vahel. Mehed hoi dsid terve öö lõket Iõõmavana. Kaks meest oli karjaga eemal, kuid ka teised ei tahtnud kuidagi magama heita. $\mathrm{N}$ ad kuulasid Ejgeli laulmist ja Vatap jutustas legendi veel ühest tšuktši koletisest keligust.

Need on hiiglaslikud, tohutu suurte lõugade, kõrgete jal gade ja pika sabaga loomad, kes elavad Tšuktši mägismaal. Nendejal gadel on tohutud küünised. Kõige hirmsam on aga koletise suu, mis on nii suur, et sinna mahub sisse mees koos põdrarakendiga. Kui keegi vaatab kel igule otsa, on temaga lõpp, sest keligu pilk lausa halvab inimese või looma - see tardub paigale ja saab kel igu saagiks.

Keegi karjus, kes oli läinud üksinda otsima kadunud põhjapõtru, oli näinud keligud. Ta sai aru, et keligu eest ära joosta ei jõua, ning teadis ka, et ei tohi kol etisele otsa vaadata. Selleks, et keligule mitte otsa vaadata, otsustas ta looma naerma ajada, ning hoides oma pilku maas, ütles keligule:

“Keligu, naerata ometi! Vaata, kui suur ja paks ma olen. Sa võid mind ära süüa. Tead, keligu, mul on kodus palju põtru. Need on paksud ja rasvased. Sa saad nendest mitu päeva süüa."

Keligu hakkas muidugi naerma: "Ha-ha-haa!" Tema metsik naer kõlas sopkade vahel nii, et kivid kaljudelt varisesid. Keligul olid suured Iõuad, mis naerdes avanesid. Alumine lõualuu ulatus maani ja ülemine peaaegu seljani. Kui Iõuad olid avatud, ei näinud keligu midagi, sest ülemised lõuad katsid silmad kinni. Karjus pistis jooksu. Keligu pi di lõuad oma suurtekäppadega sulgema, enne kui sai edasi minna, sest alumine lõug toetus maha ja takistas liikumist ning ülemise tagant ta ei näinud midagi. Lõugade sulgemine võttis kel igul aega. N eed lõpuks kinni saanud, tormas ta karjusele järele.

Kui karjus märkas, et keligu jõuab talle järele, jäi ta seisma, hoi dis pilku maas ja ütles jälle: “Keligu, sul on täna väga tore päev. Vaata, kui rasvane ma olen. Sa võid mind ära süüa. Mul on kodus palju põtru. Nad kõik on ka rasvased. Sa võid nad kõik ära süüa. Naerata ometi! Sa saad mitu päeva põhjapõtraderasvast liha süüa. Naera, sul on nii tore päev!" 
Keligu hakkas naerma: "Ha-ha-haa". Lõuad avanesid. Üks toetus maha ja teine varjas nägemise. Karjus aga jooksis nii kuidas jalad võtsid kodu poole. Keligul läks jälletükk aega, ennekui ta sai oma lõuad suletud ja karjuselejäreletormatud. Nii juhtus mitmeid kordi.

Lõpuks jõuti jarangade juurde, kus hulk noori jahimehi oli kisa peale jarangadest väljunud. Nad tapsid selle keligu, aga neid pidi aegajalt ikka mägedes liikuma.

J elole meenus selle peale eesti lugu põhjakonnast, millest ta teistele jutustas. Tšuktšid olid kuulamise järel nõus, et tegemist on ühe ja sama loomaga või vähemalt sugulastega, sest üks jooksis ja teine hüppas, aga välimuselt olid nad sarnased.

Hommikul tahtis J elo minna jääkaru otsima, kuid teised keelasid teda, öeldes, et ta peab karjaga minema ja neil ei ole aega teda ootama jääda. Peal egi, kui ketlja ol eks tahtnud, ol eks ta selle amka juba eelmisel päeval kättesaanud, muidugi kui see üldse oli amka. Ei olnud midagi teha. J elo unistus kodu kaunistavast jääkarunahast jäigi unistuseks.

Miks jääkarud satuvad rändama, sellest lugesin juba E estis olles 1977. aasta 15. detsembri ajal ehest Edasi, kus aval dati TASSi teadaanne "J ääkaruderännuteelt".

Ligi kuu aega piirasid Billingsi nemetipus paiknevat küla jääkarud. Kuigi loomad käitusid rahulikult, hingati kergendatult, kui kutsumata külalised hakkasid lahkuma. Sügiseti polePõhja-J äämererannikul kohtumineArktika hulkuritega sugugi haruldane. Kuid et jääkarusid ol eks kogunenud rohkem kui 40, seda ei mäleta si in ka kõigevanemad inimesed.

“J ääkarusid med itasid kohal e vaalade ja teiste ookeaniel anikekorjused, milletorm ol i kaldalehei tnud," ütles Magadanis asuva Põhja pi irkondade Biol oogi listeProblemi deTeadusliku Uurimisel nstituudi vanemteadur bi oloogiakandidaat A. Kretšmar.

"Billingsi neem paikneb teel, mida mööda jääkarud liiguvad Wrangeli saarele, kus riiklikul kaitsealal on jääkarude"sünnitusmaja". I gal aastal ehitavad umbes 200 emakaru saarele koopad, kus nad toovad il mal eoma järel tulijaid ja toi davad neid. Sel aastal jäätus Longi väin, mis eraldab saart mandrist ebatavalisel t hilja, ning seesundis loomadel teed katkestama ja vahepeal puhkama." 